\title{
Safety of oral methylnaltrexone for opioid- induced constipation in patients with chronic noncancer pain
}

This article was published in the following Dove Press journal: Journal of Pain Research

\author{
Richard L Rauck' \\ Neal E Slatkin ${ }^{2,3}$ \\ Nancy Stambler ${ }^{4}$ \\ Robert J Israel ${ }^{3}$
}

'Carolinas Pain Institute, WinstonSalem, NC, USA; ${ }^{2}$ School of Medicine, University of California Riverside, Riverside, CA, USA; ${ }^{3}$ Medical Affairs, Salix Pharmaceuticals, Bridgewater, NJ, USA; ${ }^{4}$ Clinical Research, Progenics Pharmaceuticals, New York, NY, USA

Correspondence: Richard L Rauck Carolinas Pain Institute, 145 Kimel Park Drive - suite 330, Winston-Salem, NC 27103, USA

$\mathrm{Tel}+\mathrm{I} 3367 \mid 4838$ I

Fax +I 3367658492

Email RRauck@ccrpain.com
Purpose: Oral methylnaltrexone was shown to be effective in treating opioid-induced constipation (OIC) in patients with chronic noncancer pain in a Phase III randomized controlled trial. This report provides a detailed safety analysis from that study.

Methods: Adults ( $n=803$ ) with chronic noncancer pain for $\geq 2$ months and confirmed OIC while receiving opioid doses $\geq 50 \mathrm{mg}$ morphine equivalent per day for $\geq 14$ days were randomized 1:1:1:1 to oral methylnaltrexone $(150,300$, or $450 \mathrm{mg})$ or placebo once daily for 4 weeks, followed by as-needed use for 8 weeks. Safety was evaluated by examining treatment-emergent adverse events (TEAEs), clinical laboratory parameters, vital signs, electrocardiography, rescuelaxative and opioid use, Objective Opioid Withdrawal Scale (OOWS) and Subjective Opioid Withdrawal Scale (SOWS), and pain-intensity scores.

Results: TEAEs occurred at a similar incidence in the methylnaltrexone groups (59.0\%) and placebo group (63.0\%). The most common TEAEs with methylnaltrexone were abdominal pain $(8.0 \% \mathrm{vs}$ $8.5 \%$ with placebo), nausea (6.8\% vs $9.0 \%$ ), and diarrhea (6.0\% vs 3.5\%). Cardiac-related TEAEs occurred in $1.8 \%$ and $1.0 \%$ of patients, respectively, and no major adverse cardiovascular events were reported. No patient had a cluster of TEAEs associated with opioid withdrawal after excluding gastrointestinal TEAEs. Changes in laboratory parameters, vital signs, and electrocardiography were generally small and similar across treatment groups. Rescue-laxative use was more common with placebo than methylnaltrexone $450 \mathrm{mg}$ ( $6.20 \%$ vs $4.27 \%$ of study days, $P=0.024)$. Changes in opioid dose, OOWS and SOWS scores, and pain-intensity scores during treatment were minimal. Conclusion: Oral methylnaltrexone had a safety profile comparable with placebo in the treatment of OIC in patients with chronic noncancer pain, with no evidence of cardiac toxicity or opioid withdrawal.

Keywords: analgesia, $\mu$-opioid-receptor antagonist, nonmalignant, safety

\section{Introduction}

An estimated 116 million US adults suffer from chronic pain according to the Institute of Medicine, which compromises quality of life and adds $\$ 560-\$ 635$ billion annually to societal costs. ${ }^{1}$ Many conditions are commonly associated with chronic pain, including low-back pain, osteoarthritis, and various neuropathic pain states. ${ }^{2}$ Opioid analgesics are effective for carefully selected and monitored patients with chronic noncancer pain who have not achieved sufficient pain relief with optimization of nonopioid medications. ${ }^{3,4}$ Opioids are often used for chronic noncancer pain; however, side effects of opioid-induced constipation (OIC) frequently complicate patient management.

OIC results largely from activation of enteric $\mu$-opioid receptors that reduces neurotransmitter release from enteric nerves in the gastrointestinal (GI) tract, delays 
GI transit time, stimulates nonpropulsive GI motor activity, increases intestinal muscle tone and fluid absorption, and reduces electrolyte and water secretion into the intestinal lumen. ${ }^{5}$ Clinically, OIC is characterized by reduced frequency of spontaneous bowel movements, straining, hard stools, and the sensation of incomplete evacuation and, thus, is similar in clinical presentation to functional constipation, except that it occurs during opioid treatment. ${ }^{6}$ In a systematic review of controlled clinical trials evaluating the efficacy and safety of opioid use for chronic noncancer pain, constipation was the most common adverse event (AE) encountered, affecting $41 \%$ of patients treated with opioids compared with $11 \%$ of patients receiving placebo. ${ }^{7}$ OIC may be so bothersome that patients may reduce or discontinue opioid use, thereby compromising pain control, in an effort to reduce constipation. ${ }^{8-10}$ Laxatives/enemas are generally inadequate in providing relief, because they do not reverse the underlying pathophysiology or may themselves cause side effects. . $^{8,9,11,12}$

Methylnaltrexone (Relistor ${ }^{\circledR}$; Salix Pharmaceuticals, a division of Valeant Pharmaceuticals North America, Bridgewater, NJ, USA) is a peripherally-acting $\mu$-opioid-receptor antagonist that reverses opioid-induced effects in the GI tract, including delayed gastric emptying and prolonged oral-cecal transit time, without affecting opioid analgesia. ${ }^{13-16}$ Methylnaltrexone administered by subcutaneous injection is approved by the US Food and Drug Administration (FDA) for the treatment of OIC in adults with advanced illness or pain caused by active cancer who require opioid-dosage escalation for palliative care and for the treatment of OIC in adults with chronic noncancer pain, including those with chronic pain related to prior cancer or its treatment who do not require frequent opioid-dosage escalation. ${ }^{17}$ Clinical studies and meta-analyses support the efficacy and safety of subcutaneous methylnaltrexone for these uses. ${ }^{18-21}$ An oral tablet formulation of methylnaltrexone was developed to make it more convenient for patients requiring long-term management of OIC. In a Phase III randomized controlled trial, oral methylnaltrexone $300 \mathrm{mg}$ and $450 \mathrm{mg}$ once daily compared with placebo significantly improved the percentage of dosing days resulting in a rescue-free bowel movement (RFBM) within 4 hours of dosing (primary end point, $P \leq 0.002$ ), percentage of responders with three or more RFBMs/week and an increase from baseline of one or more RFBMs/week during at least 3 of the first 4 weeks of treatment (secondary end point, $P \leq 0.03$ ), and change from baseline in weekly number of RFBMs (secondary end point, $P \leq 0.03) .{ }^{22}$ On the basis of these pivotal trial results, methylnaltrexone tablets were approved by the US FDA in July 2016 for the treatment of OIC in adults with chronic noncancer pain at a recommended dosage of $450 \mathrm{mg}$ once daily in the morning. ${ }^{17}$ Herein, we present a detailed safety analysis of oral methylnaltrexone from this pivotal trial.

\section{Methods}

\section{Study design and population}

Details on the study design and patient-eligibility criteria have been published. ${ }^{22}$ Briefly, this Phase III, randomized, placebo-controlled, double-blind trial was conducted at 117 US sites from September 2010 to November 2011. It consisted of a 14-day screening period, 28-day once-daily treatment period, 56-day as needed (PRN) treatment period, and 14-day follow-up period (Figure 1). The study was conducted under the principles of the International Council for Harmonization Guidelines for Good Clinical Practice and the Declaration of Helsinki and was registered on ClinicalTrials. gov (identifier NCT01186770). The study protocol and all
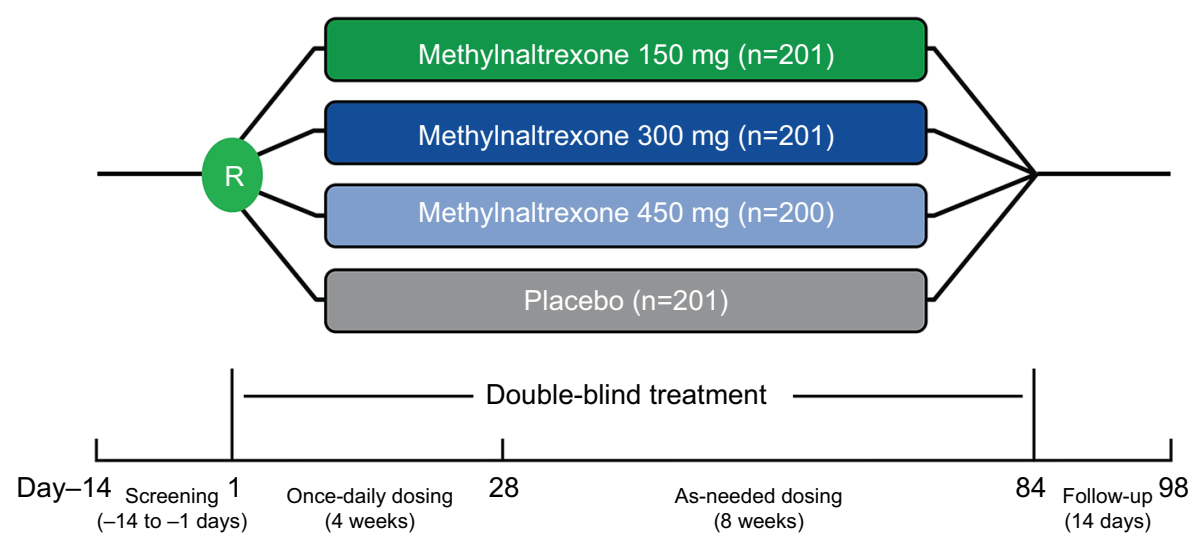

Figure I Study design

Abbreviation: R, randomization. 
amendments were reviewed and approved by appropriate institutional review boards prior to study initiation (Meritus Medical Center Institutional Review Board, Hagerstown, MD; Partners Human Research Committee, Boston, MA; Quorum Review IRB, Seattle, WA; Schulman Associates IRB, Cincinnati, OH; University of Utah IRB, Salt Lake City, UT, USA). All patients who participated in this trial provided written informed consent prior to enrollment in the study.

Outpatients aged $\geq 18$ years with $\geq 2$ months of chronic noncancer pain were eligible if they had been taking opioids for $\geq 1$ month, receiving a daily dose $\geq 50 \mathrm{mg}$ morphine equivalent for at least 14 days before the screening visit, had a history of constipation due to opioid use for $\geq 30$ days before the screening visit, and had been taking laxatives for $\geq 30$ days. Constipation was defined as having fewer than three RFBMs per week on average over the last 4 weeks, with at least one of the following symptoms present in $\geq 25 \%$ of bowel movements: hard or lumpy stools (ie, Bristol stool form type 1 or 2), straining during bowel movements, or sensation of incomplete evacuation. Eligible patients were otherwise medically stable (with a calculated creatinine clearance $\geq 30$ $\mathrm{mL} / \mathrm{min}$ ), had no history of chronic constipation before opioids were initiated, and agreed to discontinue prior laxatives and use only study-permitted laxatives throughout the study. All patients provided written informed consent before participating. Patients with a history of mechanical bowel obstruction, megacolon, clinically significant GI disease, rectal bleeding within 60 days of screening that was not associated with hemorrhoids or fissure, planned surgery, or those who were using opioid partial agonists or agonist-antagonist combinations were excluded.

Eligible patients with confirmed OIC were randomized 1:1:1:1 to receive placebo or methylnaltrexone $150 \mathrm{mg} /$ day, 300 $\mathrm{mg} /$ day, or $450 \mathrm{mg} /$ day for 4 weeks. The randomization was computer-generated and accessed using an interactive voiceresponse system. To maintain blinding, all patients took three tablets per day, first thing in the morning, on an empty stomach, during the 28-day once-daily treatment period, and then PRN during the 56-day PRN treatment period, but not more than once daily. Study medication was to be taken at least $30 \mathrm{~min}$ utes before breakfast. Rescue-laxative therapy (up to three oral bisacodyl tablets) was permitted for patients having no bowel movements for 3 consecutive days. If no laxation was obtained, an enema or an additional dose of bisacodyl was permitted.

\section{Safety end points}

Safety was monitored by the incidence of treatment-emergent AEs (TEAEs), including those from the cardiac system-organ class, which were of special interest, severe AEs, serious TEAEs, drug-related TEAEs (as determined by the investigator), and TEAEs leading to discontinuation. Safety was also evaluated in terms of changes from baseline in clinical laboratory parameters, vital-sign measurements, and electrocardiography (ECG) measurements (including incidence of abnormal ECG), and use of rescue laxatives and opioid medications (expressed as morphine equivalents). In addition, changes from baseline in opioid-withdrawal symptoms and pain intensity were assessed at all study visits during the treatment period. Evidence of opioid withdrawal was assessed using total scores on the 13-item Objective Opioid Withdrawal Scale (OOWS) and 19-item Subjective Opioid Withdrawal Scale (SOWS). ${ }^{23}$ The OOWS was completed by a trained clinician, whereas the SOWS was completed by the patient. Because these scales include terms assessing abdominal cramping, a known opioid-withdrawal symptom that may also be caused by the induction of laxation with methylnaltrexone in patients with OIC, analyses of these two scales were performed with and without the items relating to cramping. The item referring to feeling "like shooting up" was considered inappropriate for the nonaddict study population and was thus substituted with an item referring to feeling "like taking more pain medication." Pain intensity during the previous 24-hour period was evaluated by the patient using an 11-point Likert scale ranging from 0 (none) to 10 (worst pain possible).

\section{Statistical analyses}

Safety analyses were conducted for all randomized patients who received one or more doses of the study drug. TEAEs were coded using the Medical Dictionary for Regulatory Activities (version 13.0) and summarized by treatment group and study period. TEAEs of special interest included those relevant to cardiac safety and those possibly related to opioid withdrawal (ie, clusters of three or more withdrawal symptoms defined by Diagnostic and Statistical Manual for Mental Disorders (fifth edition [DSM5]) criteria: dysphoria, nausea/ vomiting, muscle aches, lacrimation, rhinorrhea, pupillary dilation, piloerection, sweating, diarrhea, yawning, fever, or insomnia). Analysis of TEAEs possibly related to opioid withdrawal was conducted with and without the GI-symptom items, because these symptoms are common in patients with OIC. Clinical laboratory parameters (hematology, blood chemistry, and urinalysis) and vital signs were summarized at baseline, each postbaseline time point, and end of treatment, as well as changes from baseline for numeric results. ECG parameters were summarized using descriptive statistics for 
each time point and change from baseline. The corrected QT interval (QTc) was calculated using Fridericia (QTcF), Bazett (QTcB), and linear regression (QTcL) techniques. Changes from baseline in these QTc values were compared between each methylnaltrexone group and the placebo group using an ANCOVA model with treatment as effect and baseline value as a covariate.

Use of rescue laxatives was compared between methylnaltrexone groups and placebo by ANCOVA with treatment group as effect and analysis center as a covariate. Use of opioid medication was expressed in terms of average daily oral morphine equivalents and summarized by month and treatment group. Changes from baseline in total OOWS score, total SOWS score, and pain-intensity score were compared between methylnaltrexone groups and placebo using the Wilcoxon-Mann-Whitney test.

\section{Results}

\section{Patient disposition and characteristics}

The safety population consisted of 803 patients. The majority of patients in each treatment group completed the 28-day once-daily treatment period, including 180 of $201(89.6 \%)$ in the placebo group and 543 of $603(90.0 \%)$ in the combined methylnaltrexone groups. Similarly, the majority of patients entering the 56-day PRN treatment period completed that period, including 143 of $167(85.6 \%)$ in the placebo group and 464 of $527(88.0 \%)$ in the methylnaltrexone groups. The most common reason for discontinuing treatment during the once-daily period was patient request $(3.0 \%$ in the placebo group and $3.6 \%$ in the methylnaltrexone groups), whereas the most common reasons during the PRN period were protocol violation (2.4\% and $3.6 \%$, respectively), lost to follow-up (4.8\% and $3.4 \%$, respectively), and patient request $(4.2 \%$ and $2.5 \%$, respectively).

Demographic and baseline characteristics were similar among the four treatment groups (Table 1). Overall, the study population had a mean age of 51.6 years. The majority of patients were female $(62.9 \%)$, white $(82.2 \%)$, and receiving opioid treatment for back pain $(68.2 \%)$. The median daily opioid dose ranged from 141.1 to $177.5 \mathrm{mg}$ morphine equivalents in the methylnaltrexone groups and was 132.0 mg morphine equivalents in the placebo group. On average, patients had 1.42 RFBMs per week.

\section{Exposure}

Median exposure, defined by the interval between the last dose and first dose of study medication, was similar across all four groups during the 28-day once-daily treatment period, 56-day PRN treatment period, and entire 12-week treatment period. For these treatment periods, median exposure was 28 (1-28) days, 55 (1-71) days, and 83 (1-99) days for all methylnaltrexone patients compared with 28 (3-28) days, 55 (1-63) days, and 83 (3-91) days for the placebo group. As expected, the number of weekly doses of study medication

Table I Demographic and baseline characteristics

\begin{tabular}{|c|c|c|c|c|c|}
\hline & $\begin{array}{l}\text { Placebo } \\
(n=20 I)\end{array}$ & $\begin{array}{l}\text { Mntx I50 mg } \\
(n=20 I)\end{array}$ & $\begin{array}{l}\text { Mntx } 300 \mathrm{mg} \\
(n=201)\end{array}$ & $\begin{array}{l}\text { Mntx } 450 \mathrm{mg} \\
(n=200)\end{array}$ & $\begin{array}{l}\text { All Mntx } \\
(n=602)\end{array}$ \\
\hline Mean age (SD), years & $52.6(10.3)$ & $50.9(10.3)$ & $51.5(10.5)$ & $51.4(10.5)$ & $51.3(10.4)$ \\
\hline Age $\geq 65$ years, $n$ (\%) & $22(10.9)$ & $15(7.5)$ & $19(9.5)$ & $19(9.5)$ & $53(8.8)$ \\
\hline \multicolumn{6}{|l|}{ Sex, n (\%) } \\
\hline Male & $71(35.3)$ & $68(33.8)$ & $87(43.3)$ & $72(36.0)$ & $227(37.7)$ \\
\hline Female & $130(64.7)$ & $133(66.2)$ & $114(56.7)$ & $128(64.0)$ & $375(62.3)$ \\
\hline \multicolumn{6}{|l|}{ Race, n (\%) } \\
\hline White & $166(82.6)$ & $164(8 \mathrm{I} .6)$ & $158(78.6)$ & $172(86.0)$ & $494(82.1)$ \\
\hline Black/African-American & $27(13.4)$ & $30(14.9)$ & $38(18.9)$ & $25(12.5)$ & $93(I 5.4)$ \\
\hline Other & $8(4.0)$ & $7(3.5)$ & $5(2.5)$ & $3(1.5)$ & $15(2.5)$ \\
\hline \multicolumn{6}{|l|}{ Primary pain condition, $\mathbf{n}(\%)$} \\
\hline Back pain & $145(72.1)$ & $132(65.7)$ & $136(67.7)$ & $135(67.5)$ & $403(66.9)$ \\
\hline Arthritis & $12(6.0)$ & $20(10.0)$ & $15(7.5)$ & $19(9.5)$ & $54(9.0)$ \\
\hline Neurologic/neuropathic pain & II (5.5) & $16(8.0)$ & $13(6.5)$ & $16(8.0)$ & $45(7.5)$ \\
\hline Joint/extremity pain & $10(5.0)$ & $13(6.5)$ & $16(8.0)$ & II (5.5) & $40(6.6)$ \\
\hline Fibromyalgia & $12(6.0)$ & $15(7.5)$ & $8(4.0)$ & II (5.5) & $34(5.6)$ \\
\hline Other & II (5.5) & $5(2.5)$ & $13(6.5)$ & $8(4.0)$ & $26(4.3)$ \\
\hline $\begin{array}{l}\text { Median morphine-equivalent } \\
\text { opioid dose, } \mathrm{mg} / \text { day }\end{array}$ & $\begin{array}{l}132.0 \\
(42.6-1,077.3)\end{array}$ & $\begin{array}{l}141.1 \\
(30.0-1,280.0)\end{array}$ & $\begin{array}{l}177.5 \\
(47.4-2,289.3)\end{array}$ & $\begin{array}{l}155.6 \\
(27.0-1,272.0)\end{array}$ & $\begin{array}{l}151.0 \\
(27.0-2,289.3)\end{array}$ \\
\hline Mean RFBMs per week (SD) & $1.49(1.05)$ & $1.46(0.91)$ & $\mathrm{I} .35(0.89)$ & $\mathrm{I} .37(0.79)$ & $1.40(0.87)$ \\
\hline
\end{tabular}

Abbreviations: Mntx, methylnaltrexone; RFBMs, rescue-free bowel movements. 
decreased from the once-daily to the PRN treatment period. Overall, $84.7 \%$ of patients in the methylnaltrexone groups and $81.1 \%$ of those in the placebo group took six to seven doses per week during the once-daily treatment period compared with $43.6 \%$ and $42.5 \%$ of patients, respectively, during the PRN treatment period.

\section{AEs}

TEAEs were reported in $59.0 \%$ of patients taking methylnaltrexone compared with $63.0 \%$ of those taking placebo (Table 2). The incidence of TEAEs was consistent across all methylnaltrexone doses (150 mg, 58.2\%; $300 \mathrm{mg}, 59.7 \%$; 450 $\mathrm{mg}, 59.0 \%$ ). The most common TEAEs in patients receiving methylnaltrexone (all doses) were abdominal pain $(8.0 \%$ vs $8.5 \%$ with placebo), nausea ( $6.8 \%$ vs $9.0 \%)$, and diarrhea $(6.0 \%$ vs $3.5 \%$ ), and of these, abdominal pain and diarrhea appeared to increase in incidence with increasing methylnaltrexone dosage.

After the first dose of study medication, abdominal pain, diarrhea, and nausea were more prevalent with oral methylnaltrexone $450 \mathrm{mg}$ compared with placebo and the lower meth- ylnaltrexone doses (Table 3). Following the second dose of study medication, the incidence of abdominal pain, diarrhea, and nausea were similar among all treatment groups (Table 3). The incidence of AEs of interest (abdominal pain, diarrhea, hyperhidrosis, anxiety, nausea) was $\leq 1.5 \%$ in all treatment groups for each dose $>2$ through dose 28 . Most TEAEs were mild to moderate in intensity. Severe TEAEs were reported in $8.3 \%$ of patients treated with methylnaltrexone and $9.0 \%$ of those treated with placebo. The most common severe TEAEs with methylnaltrexone overall vs placebo were diarrhea $(1.7 \%$ vs $1.0 \%$ ) and abdominal pain ( $1.2 \%$ vs $1.0 \%)$, respectively. In the daily-treatment period in the all-methylnaltrexone group, TEAEs led to study discontinuation in 12 patients $(2.0 \%)$ during the daily-dosing period and six patients $(1.0 \%)$ during the PRN dosing period. TEAEs led to discontinuation in six patients (3.0\%) and three patients $(1.5 \%)$ in the placebo group during the daily and PRN dosing periods, respectively. Discontinuations due to TEAEs that occurred in two or more patients in the methylnaltrexone vs placebo groups were diarrhea ( $n=3$ vs $n=1)$, abdominal pain ( $n=2$ vs $n=0)$,

Table 2 TEAEs occurring in $\geq 2 \%$ of patients in any treatment group, $\mathrm{n}$ (\%)

\begin{tabular}{|c|c|c|c|c|c|}
\hline & $\begin{array}{l}\text { Placebo } \\
(n=201)\end{array}$ & $\begin{array}{l}\text { Mntx I50 mg } \\
(n=20 I)\end{array}$ & $\begin{array}{l}\text { Mntx } 300 \mathrm{mg} \\
(\mathrm{n}=20 \mathrm{I})\end{array}$ & $\begin{array}{l}\text { Mntx } 450 \mathrm{mg} \\
(\mathrm{n}=200)\end{array}$ & $\begin{array}{l}\text { All Mntx } \\
(n=602)\end{array}$ \\
\hline One or more TEAEs & $127(63.2)$ & $117(58.2)$ & $120(59.7)$ & II $8(59.0)$ & $355(59.0)$ \\
\hline TEAEs of severe intensity & $18(9.0)$ & $17(8.5)$ & $16(8.0)$ & $17(8.5)$ & $50(8.3)$ \\
\hline Treatment-related TEAEs & $46(22.9)$ & $34(16.9)$ & $49(24.4)$ & $50(25.0)$ & $133(22.1)$ \\
\hline Serious AEs (SAEs) & $8(4.0)$ & $5(2.5)$ & $6(3.0)$ & $4(2.0)$ & $15(2.5)$ \\
\hline Treatment-related SAEs & 0 & 0 & 0 & 0 & 0 \\
\hline Discontinuations due to TEAEs & $9(4.5)$ & $2(1.0)$ & $9(4.5)$ & $7(3.5)$ & $18(3.0)$ \\
\hline Deaths & 0 & 0 & 0 & 0 & 0 \\
\hline \multicolumn{6}{|l|}{ Most common TEAEs } \\
\hline Abdominal pain & $17(8.5)$ & II (5.5) & $16(8.0)$ & $21(10.5)$ & $48(8.0)$ \\
\hline Nausea & $18(9.0)$ & $13(6.5)$ & $16(8.0)$ & $12(6.0)$ & $4 I(6.8)$ \\
\hline Diarrhea & $7(3.5)$ & $7(3.5)$ & $13(6.5)$ & $16(8.0)$ & $36(6.0)$ \\
\hline Flatulence & $9(4.5)$ & II (5.5) & $7(3.5)$ & $10(5.0)$ & $28(4.7)$ \\
\hline Upper respiratory tract infection & $9(4.5)$ & $9(4.5)$ & $7(3.5)$ & $8(4.0)$ & $24(4.0)$ \\
\hline Back pain & $7(3.5)$ & $12(6.0)$ & $6(3.0)$ & $5(2.5)$ & $23(3.8)$ \\
\hline Urinary tract infection & $7(3.5)$ & $7(3.5)$ & $8(4.0)$ & $7(3.5)$ & $22(3.7)$ \\
\hline Anxiety & $3(1.5)$ & $6(3.0)$ & $9(4.5)$ & $7(3.5)$ & $22(3.7)$ \\
\hline Hyperhidrosis & $4(2.0)$ & $6(3.0)$ & $8(4.0)$ & $6(3.0)$ & $20(3.3)$ \\
\hline Headache & $8(4.0)$ & $2(1.0)$ & $8(4.0)$ & $9(4.5)$ & $19(3.2)$ \\
\hline Vomiting & $9(4.5)$ & $3(1.5)$ & $6(3.0)$ & $7(3.5)$ & $16(2.7)$ \\
\hline Abdominal pain, upper & $7(3.5)$ & $4(2.0)$ & $6(3.0)$ & $6(3.0)$ & $16(2.7)$ \\
\hline Arthralgia & $4(2.0)$ & $7(3.5)$ & $5(2.5)$ & $4(2.0)$ & $16(2.7)$ \\
\hline Abdominal distension & $6(3.0)$ & $6(3.0)$ & $3(1.5)$ & $7(3.5)$ & $16(2.7)$ \\
\hline Sinusitis & $4(2.0)$ & $5(2.5)$ & $7(3.5)$ & $2(1.0)$ & I4 (2.3) \\
\hline Rhinorrhea & $3(1.5)$ & $5(2.5)$ & $4(2.0)$ & $4(2.0)$ & $13(2.2)$ \\
\hline Influenza & $5(2.5)$ & $4(2.0)$ & $6(3.0)$ & $2(1.0)$ & $12(2.0)$ \\
\hline Hot flush & $4(2.0)$ & $2(1.0)$ & $2(1.0)$ & $2(1.0)$ & $6(1.0)$ \\
\hline Abdominal discomfort & $4(2.0)$ & $2(1.0)$ & 0 & $\mathrm{I}(0.5)$ & $3(0.5)$ \\
\hline Tremor & $\mathrm{I}(0.5)$ & $7(3.5)$ & $4(2.0)$ & $3(1.5)$ & $14(2.3)$ \\
\hline
\end{tabular}

Abbreviations: Mntx, methylnaltrexone; TEAEs, treatment-emergent adverse events. 
and dyspnea ( $\mathrm{n}=2$ vs $\mathrm{n}=0$ ), respectively. All TEAEs leading to discontinuation resolved, except for abdominal pain in a patient taking methylnaltrexone $300 \mathrm{mg}$, vertigo in a patient taking methylnaltrexone $450 \mathrm{mg}$, and urticaria in a patient taking placebo. No patients died during the study.

Drug-related TEAEs (Table 4) most commonly involved disorders from the GI system-organ class (methylnaltrexone groups $13 \%-22 \%$, placebo $15 \%$ ). Over the entire 12 -week study, drug-related TEAEs that occurred at a frequency $\geq 2 \%$ in the all-methylnaltrexone group vs the placebo group were abdominal pain $(6.1 \%$ vs $5.0 \%)$, nausea $(4.8 \%$ vs $4.0 \%)$, flatulence $(4.3 \%$ vs $3.0 \%)$, diarrhea $(3.7 \%$ vs $0.5 \%)$, upper abdominal pain $(2.2 \%$ vs $3.0 \%)$, and abdominal distension $(2.2 \%$ vs $2.0 \%)$, respectively. During the 4-week daily-dosing period, drug-related TEAEs were similar in the overall group taking methylnaltrexone (18\%) compared with those taking placebo (18\%). Drug-related TEAEs occurred in higher percentages of patients treated with the two higher methylnaltrexone doses: $19 \%$ and $22 \%$ in the methylnaltrexone 300 $\mathrm{mg}$ and $450 \mathrm{mg}$ groups, respectively, compared with $14 \%$ with methylnaltrexone $150 \mathrm{mg}$. Drug-related AE frequency during the PRN period was lower than that found during the 4-week daily-dosing period, and occurred in 7\% in those taking methylnaltrexone or placebo.

TEAEs of special interest included those related to cardiac safety and opioid withdrawal. The incidence of cardiac TEAEs with methylnaltrexone $(1.8 \%)$ was similar to that with placebo $(1.0 \%)$, and none led to treatment discontinuation (Table 5). One patient in the placebo group had a cardiac serious AE (SAE; atrial flutter), while no patient treated with methylnaltrexone had a cardiac SAE. No major cardiovascular AEs occurred during the study. Five patients $(0.8 \%)$ in the methylnaltrexone groups compared with none in the placebo group had a cluster of TEAEs suggestive of

Table 3 Occurrence of $A E$ of interest by oral methylnaltrexone dose

\begin{tabular}{|c|c|c|c|c|c|}
\hline & \multicolumn{5}{|l|}{ AE, n (\%) } \\
\hline & Abdominal pain & Diarrhea & Hyperhidrosis & Anxiety & Nausea \\
\hline \multicolumn{6}{|l|}{ After first dose } \\
\hline $150 \mathrm{mg}(\mathrm{n}=20 \mathrm{I})$ & $4(2.0)$ & 0 & $\mathrm{I}(0.5)$ & 0 & $\mathrm{I}(0.5)$ \\
\hline $300 \mathrm{mg}(\mathrm{n}=20 \mathrm{I})$ & $7(3.5)$ & 0 & $2(1.0)$ & $5(2.5)$ & $5(2.5)$ \\
\hline $450 \mathrm{mg}(\mathrm{n}=200)$ & $13(6.5)$ & $3(1.5)$ & $2(1.0)$ & $2(1.0)$ & $6(3.0)$ \\
\hline Placebo $(n=20 I)$ & $4(2.0)$ & 0 & 0 & 0 & $2(1.0)$ \\
\hline \multicolumn{6}{|c|}{ After second dose } \\
\hline $150 \mathrm{mg}(\mathrm{n}=20 \mathrm{I})$ & $2(1.0)$ & 0 & 0 & 0 & 0 \\
\hline $300 \mathrm{mg}(\mathrm{n}=20 \mathrm{I})$ & $3(1.5)$ & $\mathrm{I}(0.5)$ & $\mathrm{I}(0.5)$ & 0 & $2(1.0)$ \\
\hline $450 \mathrm{mg}(\mathrm{n}=200)$ & I (0.5) & 0 & 0 & 0 & $I(0.5)$ \\
\hline Placebo $(n=20 I)$ & $2(1.0)$ & 0 & $\mathrm{I}(0.5)$ & 0 & $3(1.5)$ \\
\hline
\end{tabular}

Abbreviation: AE/s, adverse event/s.

Table 4 Drug-related treatment-emergent adverse events ${ }^{\mathrm{a}}$ occurring in $\geq 1 \%$ of patients in any treatment group, $\mathrm{n}$ (\%)

\begin{tabular}{|c|c|c|c|c|c|}
\hline & $\begin{array}{l}\text { Placebo } \\
(n=20 I)\end{array}$ & $\begin{array}{l}\text { Mntx I } 50 \mathrm{mg} \\
(\mathrm{n}=20 \mathrm{I})\end{array}$ & $\begin{array}{l}\text { Mntx } 300 \mathrm{mg} \\
(\mathrm{n}=20 \mathrm{I})\end{array}$ & $\begin{array}{l}\text { Mntx } 450 \mathrm{mg} \\
(n=200)\end{array}$ & $\begin{array}{l}\text { All Mntx } \\
(n=602)\end{array}$ \\
\hline Any system-organ class & $44(22.9)$ & $34(16.9)$ & $49(24.4)$ & $50(25.0)$ & $133(22.1)$ \\
\hline Abdominal pain & $10(5.0)$ & $8(4.0)$ & $\mathrm{II}(5.5)$ & $18(9.0)$ & $37(6.1)$ \\
\hline Nausea & $8(4.0)$ & $7(3.5)$ & II (5.5) & II (5.5) & $29(4.8)$ \\
\hline Flatulence & $6(3.0)$ & $9(4.5)$ & $7(3.5)$ & $10(5.0)$ & $26(4.3)$ \\
\hline Diarrhea & $\mathrm{I}(0.5)$ & 0 & $9(4.5)$ & $13(6.5)$ & $22(3.7)$ \\
\hline Abdominal pain, upper & $6(3.0)$ & $3(1.5)$ & $6(3.0)$ & $4(2.0)$ & $13(2.2)$ \\
\hline Abdominal distension & $4(2.0)$ & $4(2.0)$ & $3(1.5)$ & $6(3.0)$ & I3 (2.2) \\
\hline Hyperhidrosis & $2(1.0)$ & $\mathrm{I}(0.5)$ & $3(1.5)$ & $5(2.5)$ & $9(1.5)$ \\
\hline Headache & $\mathrm{I}(0.5)$ & $\mathrm{I}(0.5)$ & $4(2.0)$ & $3(1.5)$ & $8(1.3)$ \\
\hline Vomiting & $2(1.0)$ & 0 & $\mathrm{I}(0.5)$ & $4(2.0)$ & $5(0.8)$ \\
\hline Dizziness & $2(1.0)$ & $\mathrm{I}(0.5)$ & $\mathrm{I}(0.5)$ & $3(1.5)$ & $5(0.8)$ \\
\hline Abdominal discomfort & $2(1.0)$ & $I(0.5)$ & 0 & $\mathrm{I}(0.5)$ & $2(0.3)$ \\
\hline Hot flush & $2(1.0)$ & 0 & 0 & $\mathrm{I}(0.5)$ & $\mathrm{I}(0.2)$ \\
\hline Blood alkaline phosphatase increase & $2(1.0)$ & 0 & 0 & $\mathrm{I}(0.5)$ & $\mathrm{I}(0.2)$ \\
\hline Fatigue & $2(1.0)$ & 0 & 0 & 0 & 0 \\
\hline
\end{tabular}

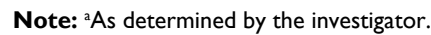

Abbreviation: Mntx, methylnaltrexone. 
Table 5 TEAEs in the cardiac disorder SOC, $\mathrm{n}(\%)$

\begin{tabular}{|c|c|c|c|c|c|}
\hline & $\begin{array}{l}\text { Placebo } \\
(n=20 I)\end{array}$ & $\begin{array}{l}\text { MntxI50 mg } \\
(n=20 I)\end{array}$ & $\begin{array}{l}\text { Mntx } 300 \mathrm{mg} \\
(\mathrm{n}=20 \mathrm{I})\end{array}$ & $\begin{array}{l}\text { Mntx } 450 \mathrm{mg} \\
(\mathrm{n}=200)\end{array}$ & $\begin{array}{l}\text { All Mntx } \\
(n=602)\end{array}$ \\
\hline One or more TEAEs & $2(1.0)$ & $2(1.0)$ & $6(3.0)$ & $3(1.5)$ & II (I.8) \\
\hline Palpitations & 0 & $2(1.0)$ & $\mathrm{I}(0.5)$ & $0(0)$ & $3(0.5)$ \\
\hline Ventricular extrasystoles & 0 & 0 & $\mathrm{I}(0.5)$ & $\mathrm{I}(0.5)$ & $2(0.3)$ \\
\hline Arrhythmia & 0 & $\mathrm{I}(0.5)$ & 0 & 0 & $\mathrm{I}(0.2)$ \\
\hline Atrial fibrillation & 0 & $\mathrm{I}(0.5)$ & 0 & 0 & $\mathrm{I}(0.2)$ \\
\hline Angina pectoris & 0 & 0 & $\mathrm{I}(0.5)$ & 0 & $\mathrm{I}(0.2)$ \\
\hline Bradycardia & 0 & 0 & $\mathrm{I}(0.5)$ & 0 & $\mathrm{I}(0.2)$ \\
\hline Bundle branch block, left & 0 & 0 & $\mathrm{I}(0.5)$ & 0 & $\mathrm{I}(0.2)$ \\
\hline Bundle branch block, right & 0 & 0 & $\mathrm{I}(0.5)$ & 0 & $\mathrm{I}(0.2)$ \\
\hline Extrasystoles & 0 & 0 & $\mathrm{I}(0.5)$ & 0 & $\mathrm{I}(0.2)$ \\
\hline Left atrial dilatation & 0 & 0 & $\mathrm{I}(0.5)$ & 0 & $\mathrm{I}(0.2)$ \\
\hline Atrioventricular block first degree & 0 & 0 & 0 & $\mathrm{I}(0.5)$ & $\mathrm{I}(0.2)$ \\
\hline Sinus tachycardia & 0 & 0 & 0 & $\mathrm{I}(0.5)$ & $\mathrm{I}(0.2)$ \\
\hline Atrial flutter & $\mathrm{I}(0.5)^{\mathrm{a}}$ & 0 & 0 & 0 & 0 \\
\hline Tachycardia & $\mathrm{I}(0.5)$ & 0 & 0 & 0 & 0 \\
\hline
\end{tabular}

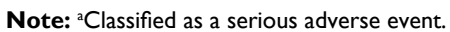

Abbreviations: Mntx, methylnaltrexone; TEAEs, treatment-emergent adverse events; SOC, system-organ class.

opioid withdrawal based on DSM5 criteria. However, when GI symptoms were excluded from the analysis because they are common in patients with OIC, no patient had a symptom cluster consistent with opioid withdrawal.

Treatment-emergent SAEs were reported in 15 patients $(2.5 \%)$ receiving methylnaltrexone and eight $(4.0 \%)$ receiving placebo. SAEs reported in two or more patients included dyspnea (methylnaltrexone $150 \mathrm{mg}, \mathrm{n}=1$; placebo, $\mathrm{n}=2$ ), noncardiac chest pain (placebo, $n=2$ ), chest pain (methylnaltrexone $300 \mathrm{mg}, \mathrm{n}=2$ ), and suicidal ideation (methylnaltrexone $150 \mathrm{mg}, \mathrm{n}=1$; methylnaltrexone $300 \mathrm{mg}, \mathrm{n}=1$ ). None was considered related to study treatment by the investigator.

\section{Clinical laboratory evaluation}

Mean changes from baseline in hematology, blood chemistry, and urinalysis parameters were small in the methylnaltrexone and placebo groups. Shifts from the normal range to either high or low values in hematology, blood chemistry, and urinalysis parameters from baseline to the end of treatment in the methylnaltrexone group were generally similar to those in the placebo groups. Shifts from normal to high uric acid were more common with methylnaltrexone (5.3\% vs $3.1 \%)$, whereas shifts from normal to high glucose were more common with placebo (3.9\% vs $8.5 \%)$. TEAEs associated with abnormal laboratory results were reported infrequently. Those occurring in $>1 \%$ of the methylnaltrexone or placebo groups included increases in creatine phosphokinase $(1.2 \%$ vs $0.5 \%)$, alanine aminotransferase (ALT) $(0.7 \%$ vs $1.5 \%)$, aspartate aminotransferase (AST) $(0.5 \%$ vs $1.5 \%)$, and alkaline phos- phatase $(0.2 \%$ vs $1.5 \%)$. No patient had ALT or AST results that were more than three times the upper limit of normal or total bilirubin value more than twice the upper limit of normal.

\section{Vital signs and electrocardiography}

Mean changes from baseline in vital signs were small: no notable differences between treatment groups were observed. Similarly, mean changes from baseline in ECG parameters were minimal and comparable between treatment groups. Increases from baseline in QTcF interval $>30 \mathrm{~ms}$ were observed in 19 patients $(3.2 \%)$ receiving methylnaltrexone compared with nine patients $(4.5 \%)$ receiving placebo, and increases from baseline $>60 \mathrm{~ms}$ were seen in six $(1.0 \%)$ and three $(1.5 \%)$ patients, respectively. Prolongation in the methylnaltrexone groups was not higher than in the placebo group. Shifts in QTcF interval to $>450 \mathrm{~ms}$ were slightly more common with methylnaltrexone (3.3\% vs $2.0 \%)$. Shifts to $>480 \mathrm{~ms}$ occurred in $0.5 \%$ of patients with each treatment. Shifts to $>500 \mathrm{~ms}$ were not reported. Similar results were seen in the analyses of QTcB and QTcL.

\section{Use of rescue laxatives and opioid medications}

Rescue laxatives were used slightly more often by patients in the placebo group than those in the methylnaltrexone groups. During the entire treatment period, rescue laxatives were used on an average of $6.20 \%$ of study days in the placebo group compared with $5.78 \%, 5.14 \%$, and $4.27 \%$ of total study days in the methylnaltrexone 150,300, and $450 \mathrm{mg}$ groups, 
respectively $(P=0.024$ for comparison of methylnaltrexone $450 \mathrm{mg}$ vs placebo).

There were minimal changes in daily opioid-medication use across treatment groups during the course of the study (Figure 2). During the 4-week once-daily treatment period, the most common opioid medications in the methylnaltrexone and placebo groups were oxycodone (33.7\% vs $32.3 \%$ ), morphine $(29.4 \%$ vs $29.4 \%$ ), hydrocodone/acetaminophen (23.9\% vs $16.9 \%$ ), and methadone ( $15.6 \%$ vs $12.9 \%$ ). These medications were also the most commonly used during the PRN treatment period.

\section{Opioid withdrawal}

Mean changes from baseline in OOWS (Figure 3) and SOWS (Figure 4) scores were minimal and comparable between methylnaltrexone and placebo over the 12-week treatment period, regardless of whether items related to cramping were included or not. Statistically significant differences between treatment groups were observed at several time points. On day 1 at 1 hour postdose, mean changes in OOWS and SOWS scores differed significantly between the methylnaltrexone $150 \mathrm{mg}$ and placebo groups (OOWS 0.06 vs $-0.07, P<0.05$; SOWS -2.83 vs $-4.45, P<0.05)$, and on day 42 , mean changes in OOWS differed between the methylnaltrexone $300 \mathrm{mg}$ and placebo groups $(-0.13$ vs $-0.02, P<0.05)$. However, these differences were not clinically meaningful, and negative score changes from baseline would indicate decreases in the number or severity of symptoms that could be associated with withdrawal.

\section{Pain-intensity scores}

There were minimal changes from baseline in mean painintensity scores across treatment groups at evaluations conducted on days $14,28,42,56$, and 84 (Figure 5). No statistically significant differences were found between the methylnaltrexone groups and placebo groups at any of the time points.

\section{Discussion}

The cause of OIC is mechanistically distinct from that of other forms of constipation, resulting largely from activation of enteric $\mu$-opioid receptors. ${ }^{5,24}$ Methylnaltrexone is a peripherally acting $\mu$-opioid-receptor antagonist, and thereby specifically addresses the underlying cause of OIC and produces predictable and consistent effects resulting in laxation. By acting peripherally, methylnaltrexone does not affect centrally mediated opioid analgesia. ${ }^{13-15}$ Methylnaltrexone was initially available as a subcutaneous formulation, but an oral formulation was developed to improve convenience for patients requiring long-term treatment of OIC.

Oral methylnaltrexone was shown to be efficacious in treating OIC in patients with chronic noncancer pain in a pivotal Phase III randomized controlled trial. ${ }^{22}$ The efficacy of oral methylnaltrexone was consistent with results from a previous Phase III trial of subcutaneous methylnaltrexone in treatment of OIC in patients with chronic noncancer pain, which included a 4-week double-blind period followed by an 8 -week open-label PRN period. ${ }^{18}$ In the present study, oral methylnaltrexone exhibited a safety profile comparable with placebo, with no evidence of cardiac toxicity, no evidence of eliciting withdrawal symptoms, and no effect on pain intensity. The safety profile of the highest oral dose tested (450 mg/day) in the present study was also favorable compared with the $12 \mathrm{mg} /$ day subcutaneous dose used in the previous Phase III trial. ${ }^{18}$ During the 4-week, daily dosing, double-blind treatment period, oral methylnaltrexone $450 \mathrm{mg}$ was associated with lower rates of TEAEs, lower rates of

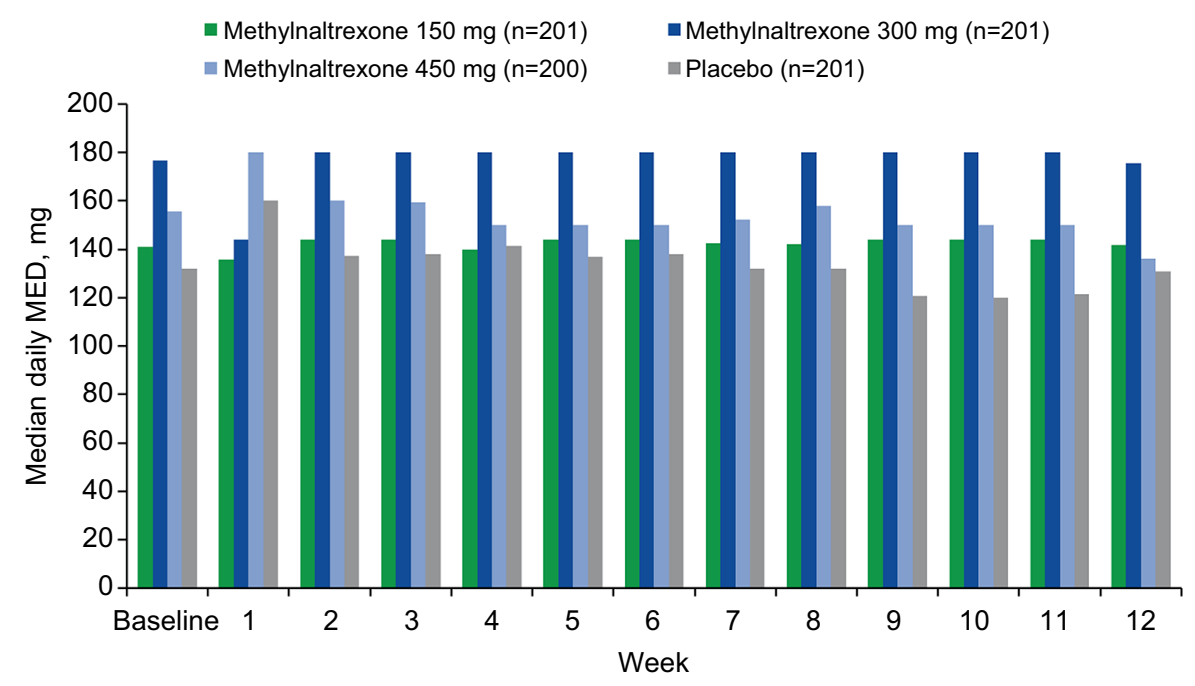

Figure 2 Median daily morphine-equivalent dose (MED) over time. 

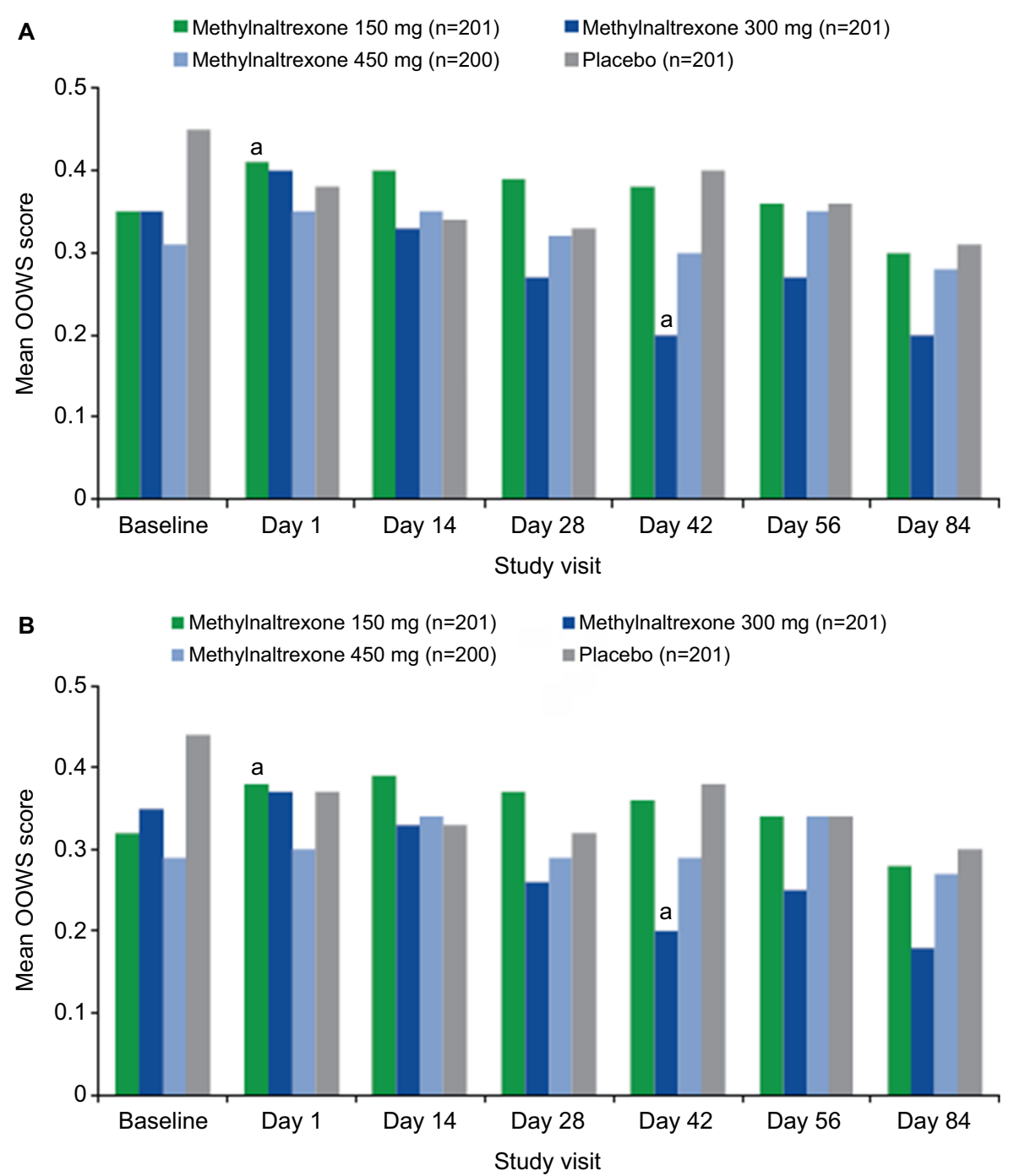

Figure 3 Mean OOWS scores over time (A) with cramping item and (B) without cramping item. Notes: ${ }^{a}<<0.05$. Minimum possible OOWS score is 0 and the maximum is $13 .{ }^{23}$ Abbreviation: OOWS, Objective Opioid Withdrawal Scale.

common TEAEs, including abdominal pain, nausea, diarrhea, and hyperhidrosis, and lower rates of discontinuations due to TEAEs compared with subcutaneous methylnaltrexone $12 \mathrm{mg}$. Rescue-laxative use, however, was lower with subcutaneous methylnaltrexone.

With both oral and subcutaneous methylnaltrexone, there was no clinically meaningful evidence of opioid withdrawal based on the OOWS or SOWS, nor was there evidence of compromised analgesia observed by changes in pain-intensity scores. ${ }^{18}$ Opioid analgesics bind to $\mu$-opioid receptors in the gut, decreasing motility and secretion of electrolytes and water, which results in constipation. ${ }^{25}$ Methylnaltrexone is a selective $\mu$-opioid-receptor antagonist that has limited ability to pass through the blood-brain barrier due to its quaternary amine structure, and acts peripherally to inhibit opioid-induced increases in oral-cecal transit time and time to gastric emptying. ${ }^{13,14,17,20,26}$ In addition, $N$-methylation of naltrexone, the parent compound of methylnaltrexone, produces a polar, positively charged species with low lipid solubility that also has restricted ability to cross the bloodbrain barrier. ${ }^{27}$ These two characteristics together enable methylnaltrexone to act locally in the GI tract while having minimal effects on analgesia or pain scores, as shown in this study.

In summary, given its efficacy, safety profile comparable to placebo, and ease of administration, oral methylnaltrexone provides a viable alternative to subcutaneous methylnaltrexone, particularly among patients with noncancer pain requiring long-term treatment of OIC or who have difficulty with administration by subcutaneous injection. 


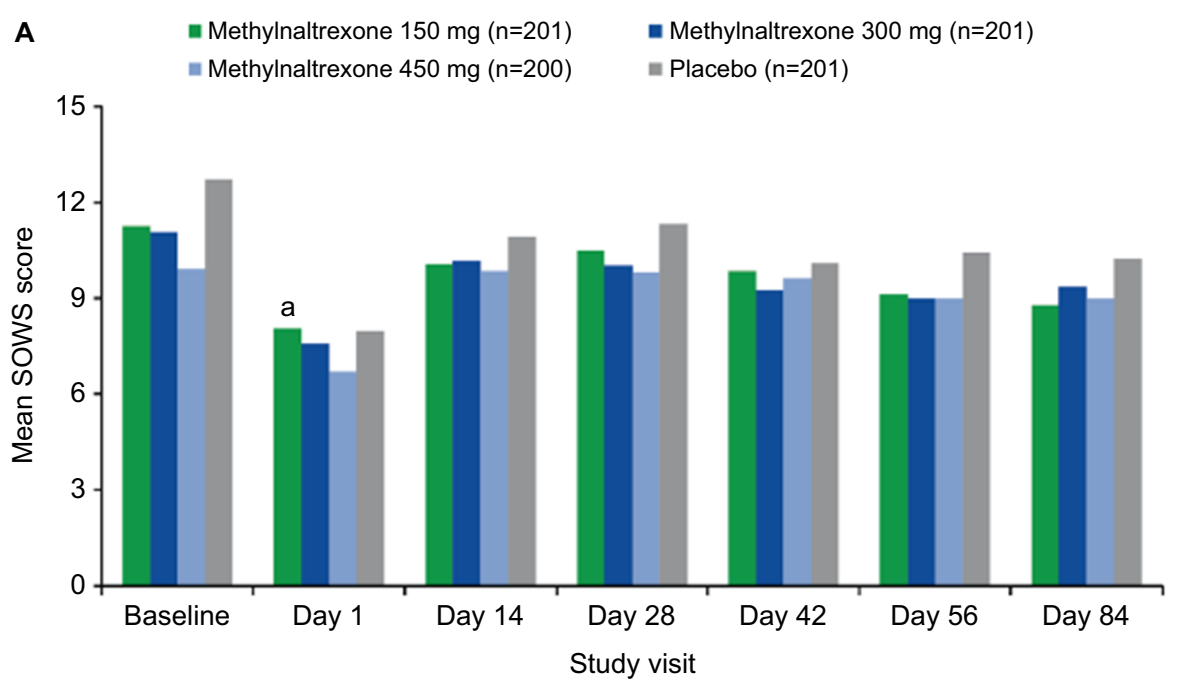

B

- Methylnaltrexone $150 \mathrm{mg}(\mathrm{n}=201)$

- Methylnaltrexone $300 \mathrm{mg}(\mathrm{n}=201)$ = Methylnaltrexone $450 \mathrm{mg}(\mathrm{n}=200)$ =Placebo $(\mathrm{n}=201)$

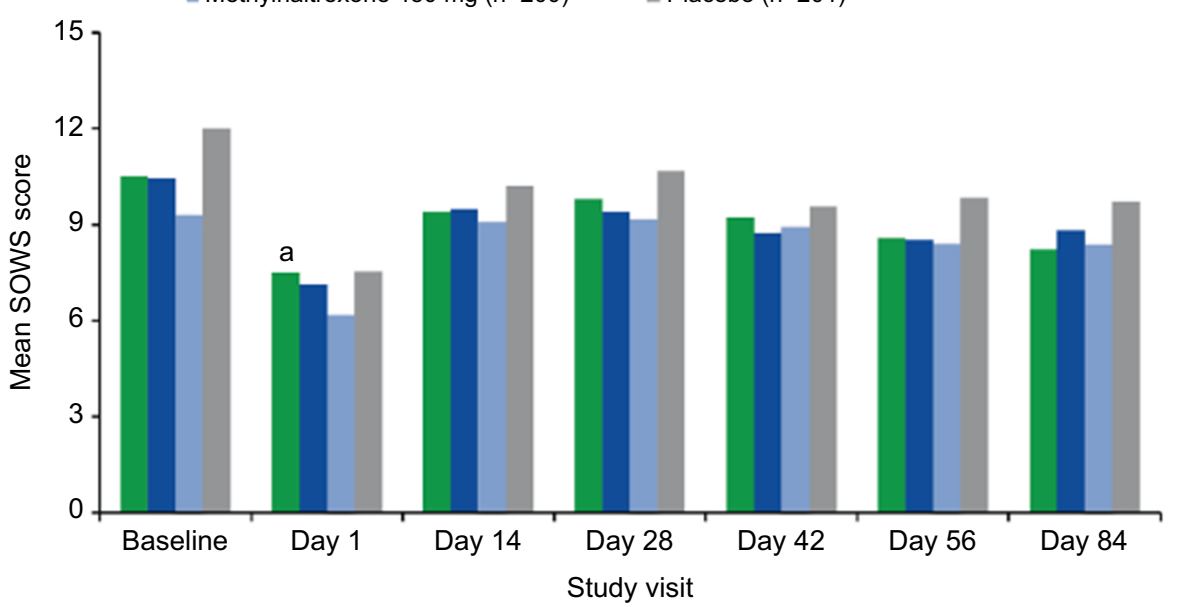

Figure 4 Mean SOWS scores over time (A) with cramping item and (B) without cramping item.

Notes: ${ }^{a} P<0.05$. The SOWS consists of 19 items that are rated on a scale of $0-4$, where 0 is not at all and 4 is extremely. The minimum score is 0 and the maximum is $76 .{ }^{23}$ Abbreviation: SOWS, Subjective Opioid Withdrawal Scale.

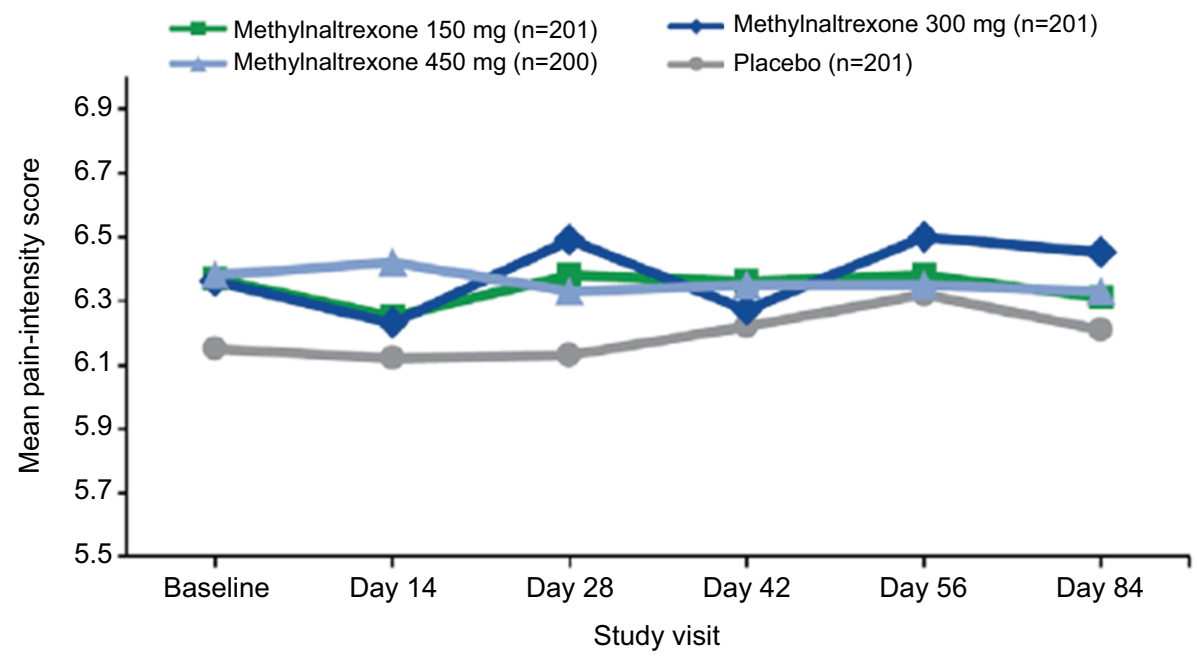

Figure 5 Mean pain-intensity scores over time.

Note: Pain rated on an $1 \mathrm{I}$-point scale ranging from 0 (none) to 10 (worst pain possible). 


\section{Data sharing statement}

The data sets generated and/or analyzed during the current study are not publicly available at this time due to the proprietary nature of this information. Requests for additional information should be made to the corresponding author.

\section{Acknowledgments}

The study was funded by Salix Pharmaceuticals, Bridgewater, NJ, USA. Progenics Pharmaceuticals, New York, NY, USA, had a role in study design, implementation of the study, and data collection. Salix had a role in data collection, data analysis, and the decision to publish. Technical editorial assistance was provided under the direction of the authors by Lisa Feder, PhD of Echelon Brand Communications, Parsippany, NJ, USA. Funding for this assistance was provided by Salix Pharmaceuticals. Details on the study design and patient eligibility criteria have been published previously. ${ }^{22}$

\section{Disclosure}

RJI is an employee of Salix (Valeant) Pharmaceuticals. RLR has received research funding from BioDelivery Sciences International, Boston Scientific Corporation, Mainstay Delivery, and Shionogi and is a consultant/speaker for AstraZeneca, Boston Scientific Corporation, Daiichi Sankyo, and Pfizer. NES has been employed by Salix Medical Affairs since July 2016, prior to which and for the preparation of all work related to the study on which this manuscript was based, he worked on behalf of Salix as an unpaid consultant, and through February 2016 was also on the Salix speakers panel. NS is a full-time employee and shareholder of Progenics Pharmaceuticals. The authors report no other conflicts of interest in this work.

\section{References}

1. Institute of Medicine. Reliving Pain in America: A Blueprint For Transforming Prevention, Care, Education, and Research. Washington, DC: The National Academies Press; 2011.

2. Gereau RW, Sluka KA, Maixner W, et al. A pain research agenda for the 21st century. J Pain. 2014;15(12):1203-1214.

3. Chou R, Fanciullo GJ, Fine PG, et al. Clinical guidelines for the use of chronic opioid therapy in chronic noncancer pain. J Pain. 2009;10(2): 113-130.

4. Busse JW, Craigie S, Juurlink DN, et al. Guideline for opioid therapy and chronic noncancer pain. CMAJ. 2017;189(18):E659-E666.

5. Camilleri M, Drossman DA, Becker G, Webster LR, Davies AN, Mawe GM. Emerging treatments in neurogastroenterology: a multidisciplinary working group consensus statement on opioid-induced constipation. Neurogastroenterol Motil. 2014;26(10):1386-1395.

6. Gaertner J, Siemens W, Camilleri M, et al. Definitions and outcome measures of clinical trials regarding opioid-induced constipation: a systematic review. J Clin Gastroenterol. 2015;49(1):9-16.

7. Kalso E, Edwards JE, Moore RA, McQuay HJ. Opioids in chronic non-cancer pain: systematic review of efficacy and safety. Pain. 2004;112(3):372-380.
8. Bell TJ, Panchal SJ, Miaskowski C, Bolge SC, Milanova T, Williamson R. The prevalence, severity, and impact of opioid-induced bowel dysfunction: results of a US and European Patient Survey (PROBE 1). Pain Med. 2009;10(1):35-42.

9. Cook SF, Lanza L, Zhou X, et al. Gastrointestinal side effects in chronic opioid users: results from a population-based survey. Aliment Pharmacol Ther. 2008;27(12):1224-1232.

10. Noble M, Tregear SJ, Treadwell JR, Schoelles K. Long-term opioid therapy for chronic noncancer pain: a systematic review and metaanalysis of efficacy and safety. J Pain Symptom Manage. 2008;35(2): 214-228.

11. Coyne KS, LoCasale RJ, Datto CJ, Sexton CC, Yeomans K, Tack J. Opioid-induced constipation in patients with chronic noncancer pain in the USA, Canada, Germany, and the UK: descriptive analysis of baseline patient-reported outcomes and retrospective chart review. Clinicoecon Outcomes Res. 2014;6:269-281.

12. Nelson AD, Camilleri M. Chronic opioid induced constipation in patients with nonmalignant pain: challenges and opportunities. Therap Adv Gastroenterol. 2015;8(4):206-220.

13. Murphy DB, Sutton JA, Prescott LF, Murphy MB. Opioid-induced delay in gastric emptying: a peripheral mechanism in humans. Anesthesiology. 1997;87(4):765-770.

14. Yuan CS, Foss JF, O'Connor M, et al. Methylnaltrexone for reversal of constipation due to chronic methadone use: a randomized controlled trial. JAMA. 2000;283(3):367-372.

15. Webster LR, Brenner DM, Barrett AC, Paterson C, Bortey E, Forbes WP. Analysis of opioid-mediated analgesia in phase III studies of methylnaltrexone for opioid-induced constipation in patients with chronic noncancer pain. J Pain Res. 2015;8:771-780.

16. Thomas J, Karver S, Cooney GA. Methylnaltrexone for opioidinduced constipation in advanced illness. N Engl J Med. 2008;328(22): 2332-2343.

17. Relistor [package insert]. Bridgewater, NJ: Salix Pharmaceuticals. 2017.

18. Michna E, Blonsky ER, Schulman S, et al. Subcutaneous methylnaltrexone for treatment of opioid-induced constipation in patients with chronic, nonmalignant pain: a randomized controlled study. J Pain. 2011;12(5):554-562.

19. Viscusi ER, Barrett AC, Paterson C, Forbes WP. Efficacy and safety of methylnaltrexone for opioid-induced constipation in patients with chronic noncancer pain: a placebo crossover analysis. Reg Anesth Pain Med. 2016;41(1):93-98.

20. Siemens W, Becker G. Methylnaltrexone for opioid-induced constipation: review and meta-analyses for objective plus subjective efficacy and safety outcomes. Ther Clin Risk Manag. 2016;12:401-412.

21. Mehta N, O'Connell K, Giambrone GP, Baqai A, Diwan S. Efficacy of methylnaltrexone for the treatment of opiod-induced constipation: a metaanalysis and systematic review. Postgrad Med. 2016;128(3):282-289.

22. Rauck R, Slatkin NE, Stambler N, Harper JR, Israel RJ. Randomized, double-blind trial of oral methylnaltrexone for the treatment of opioidinduced constipation in patients with chronic noncancer pain. Pain Pract. 2017;17(6):820-828.

23. Handelsman L, Cochrane KJ, Aronson MJ, Ness R, Rubinstein KJ, Kanof PD. Two new rating scales for opiate withdrawal. Am J Drug Alcohol Abuse. 1987;13(3):293-308.

24. Pergolizzi JV, Raffa RB, Pappagallo M, et al. Peripherally acting $\mu$-opioid receptor antagonists as treatment options for constipation in noncancer pain patients on chronic opioid therapy. Patient Prefer Adherence. 2017;11:107-119.

25. Holzer P. Opioid receptors in the gastrointestinal tract. Regul Pept. 2009;155(1-3):11-17.

26. Yuan CS, Foss JF, O’Connor M, Toledano A, Roizen MF, Moss J. Methylnaltrexone prevents morphine-induced delay in oral-cecal transit time without affecting analgesia: a double-blind randomized placebocontrolled trial. Clin Pharmacol Ther. 1996;59(4):469-475.

27. Yuan C-S, Foss JF. Methylnaltrexone: Investigation of clinical applications. Drug Dev Res. 2000;50(2):133-141. 
The Journal of Pain Research is an international, peer reviewed, open access, online journal that welcomes laboratory and clinical findings in the fields of pain research and the prevention and management of pain. Original research, reviews, symposium reports, hypothesis formation and commentaries are all considered for publication.
Dovepress

The manuscript management system is completely online and includes a very quick and fair peer-review system, which is all easy to use. Visit http://www.dovepress.com/testimonials.php to read real quotes from published authors. 